\title{
NOTE ON THE SO-CALLED SECOND BRANCHIAL ARCH IN LIZARDS.
}

\author{
By John Hewitt.
}

(With one Text-figure.)

The occurrence of an isolated cartilaginous element, apparently a branchial arch, in the neck of certain adult lizards was emphasised by Mr. F. E. Beddard in a paper "On the Anatomy of Certain Species of Squamata" ('Proc. Zool. Soc.', 1907, p. 53). This element had been previously observed by Prof. W. K. Parker in the adult skull of Lacerta agilis, but, perhaps owing to a somewhat ambiguous description ('Phil. Trans.,' 1879, p. 616), the fact has been generally overlooked by the writers of text-books on vertebrate Zoology ; there is, however, a clear account of the hyoid and branchial apparatus in T. J. Parker's chapter on the Lizard in his 'Zootomy,' p. 146.

It is commonly stated that, whereas the hyoid apparatus both of Chelonia and of Lacertilia is provided with two pairs of large horns, those of Chelonia belong to the first and second branchial arches, the hyoid arch being represented only by a small or obsolete horn, whilst in Lacertilia the two horns belong to the Hyoid and first branchial arches. As a matter of fact, the hyoidean apparatus of lizards (see Hoffmann in Bronn's 'Tierreich,' " Reptilien," p. 608, Taf. 72 ; Beddard in 'P. Z. S.,' 1905, p. 20; Shufeldt in 'P. Z. S.,' 1890 , p. $224, \mathrm{Pl} .18$ ) varies considerably, the two horns showing various degrees of development, whilst there may or may not be present a posterior bifurcation of the median piece which very probably is a persistent remnant of the second branchial arch, as thus considered by T. J. Parker. When present, this pair of basibranchial processes may be closely approximated in the middle line, or they may be widely separated as in Pachydactylus bibroni and some other geckoes; in closely allied genera they may be strongly developed or completely absent. The one character, which may point to the lack of true serial homology between these basibranchial processes and the two pairs of cornua, is the absence of any joint to mark them off from the median copula, whereas the cornua appear to be almost always articulated therewith. However, the presence of joints in the hyoidean apparatus seems to be sometimes merely a matter of function. At the anterior bend of the hyoid arch of lizards, the element is more or less completely divided into two, a dorsal and a ventral half, being completely so in Varanus, whilst, on the other hand, in Gerrhosaurus validus I have found no trace of a joint or separation into two halves. Again, in the Agamidae, as known to me in the genus Agama, the base of the hyoid arch has almost entirely fused up with the 
copula; so much so that on examining the hyoid apparatus in ventral view the hyoid and copula seem to be completely continuous, although on careful examination of these parts from the dorsal side a joint is clearly indicated.

According to the figure given by Mr. Beddard for the Agamid genus Chlamydosaurus ('P. Z. S.,' 1905, p. 20), the ventral portion of the hyoid presents the appearance of a lateral outgrowth from the copula, no demarcation between the two elements being represented, but Goniocephalus, another genus of the same family, as figured by Hoffmann in Bronn's 'Tierreich,' has a very distinct articulation marking the base of the hyoid arch.

Whatever may be the significance of the basibranchial processes in lizards, there can be no doubt but that the isolated cartilaginous elements noticed by Mr. Beddard in Zonurus giganteus (Zonuridae), in Tiliqua and Trachydosaurus (Scincidae), and in Gerrhonotus (Anguidae), represent portions of a branchial arch. According to T. J. Parker, they probably represent the epibranchial region of the second branchial arch, and Beddard also refers them to the same arch. In any case, they cannot be precisely homologous with the bar designated as the second branchial in the Chelonia - an element which, as previously stated, may really be the same as the basibranchial process of lizards. Their dorsal situation and the absence of any trace of connection between these elements and the copula apparently indicate an origin from the dorsal portion of a branchial arch, whereas the cornua and the basibranchial processes are no doubt derived from the ventral portions of the original arches. Further, it seems to me undesirable to refer this element to any particular arch at present, as the data available from dissection of an adult are insufficient for the purpose. They have no cartilaginous connection with any part of the hyoid apparatus, and it seems possible that they may be referable to any one of the arches therein represented, or to a succeeding arch. I shall therefore refer to them merely as the Epibranchials.

The results of the examination of a number of S. African lizards in search of the Epibranchials can be briefly recorded as follows:

Agamidae.-The epibranchials are absent. The whole hyoid apparatus in Agama atricollis is somewhat reduced, both cornua being rather short, and the hyoid being quite separated from the tympanic region.

Varanidae.-In Varanus the epibranchials are absent; the hyoid has no relation with the ear; the first branchial is greatly elongated.

Chamaeleonidae.-The epibranchials are absent in Chamaeleon quilensis. The anterior and posterior cornua are considerably reduced.

Gerrhosauridae.-In Gerrhosaurus validus the epibranchials are present, being sometimes very distinct and ossified. They lie more deeply than the cornua, being separated therefrom by a band of muscles. The hyoid terminates at a considerable distance from the ear, but a very slender strand of ligament passes from its end to the tympanic region. G. flavigularis offers similar characters. 
Scincidae.-Mabuia trivittata has distinct epibranchials. At the lower end of each bar is a short. forwardly-projecting process. According to Beddard, in the genus Tiliqua a ligament passes from this projecting process and is attached to the end of the hyoid cornu. The hyoid is separated from the ear.

Lacertidae.-In Nucras delalandi the whole hyoid apparatus is very much like that of $M$. trivittata. The ligamental strand between the lower portion of the epibranchial and the distal end of the hyoid is distinct.

Zonuridae.-In Zonurus giganteus, Z. cordylus and Pseudocordylus microlepidotus the epibranchials are present. The hyoid has no relation with the ear.
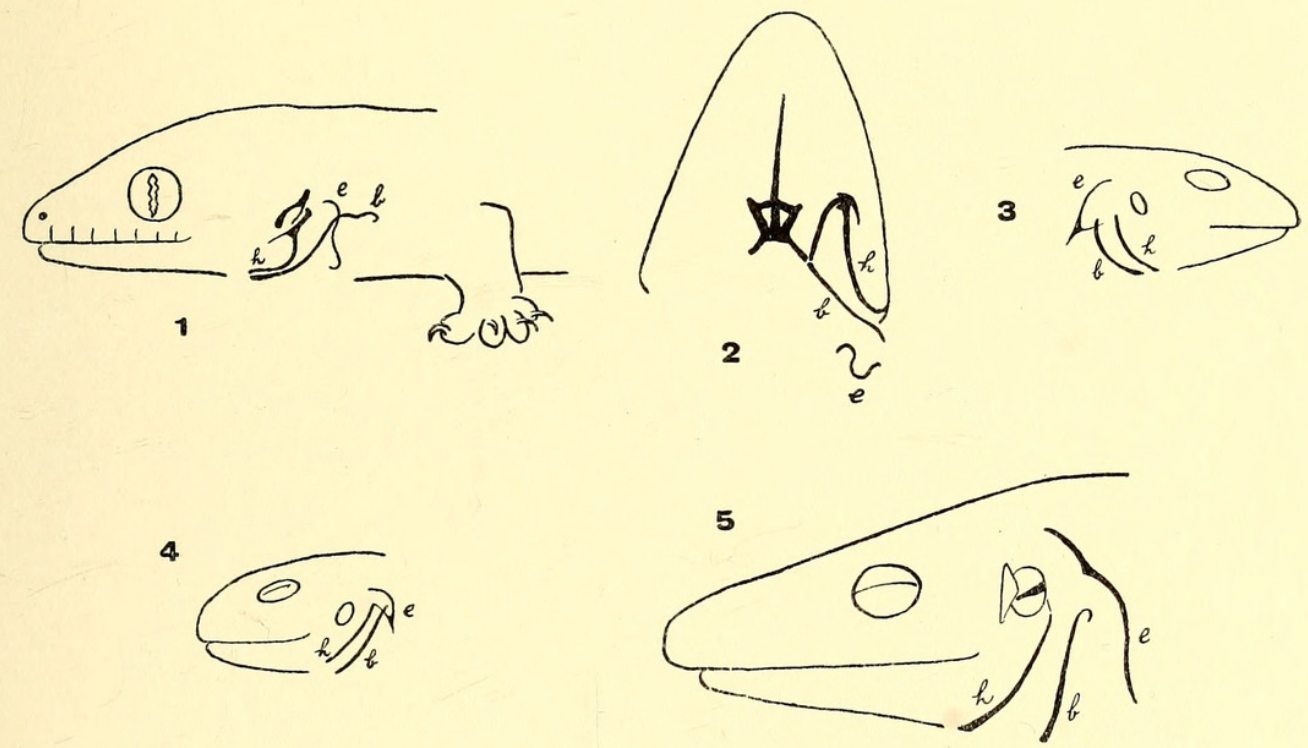

Hyobranchial apparatus of lizards. 1. Homopholis wahlbergi (fam. Geckonidae). 2. Same in ventral view. 3. Mabuia trivittata (fam. Scincidae). 4. Nucras delalandi (fam. Lacertidae). 5. Gerrhosaurus validus (fam. Gerrhosauridae). $h$. Hyoid arch. b. First branchial arch. e. Epibranchial.

Geckonidae.-In Homopholis wahlbergi and Pachydactylus bibroni the epibranchial is present as a very slender thread of cartilage. The hyoid is intimately connected with the ear, passing along the posterior side of the tympanic membrane, which alone separates it from the columella. The hyoid and columella terminate very close together on the surface of the skull.

Although as yet comparatively few genera have been examined, it seems very likely that the epibranchials are normally present in the following families of lizards: Geckonidae, Lacertidae, Zonuridae, Scincidae, Gerrhosauridae and Anguidae; and are absent from Agamidae, Varanidae, Helodermatidae and Iguanidae. Its homology can only be worked out embryologically. In the meantime, the ligamental connection between the lower portion of the epibranchial and the upper end of the hyoid cornu in certain families can be noted but not explained. 


\section{$2 \mathrm{BHL}$ Biodiversity Heritage Library}

Hewitt, John. 1919. "NOTE ON THE SO-CALLED SECOND BRANCHIAL ARCH IN LIZARDS." Transactions of the Royal Society of South Africa 8, 91-93. https://doi.org/10.1080/00359191909519985.

View This Item Online: https://www.biodiversitylibrary.org/item/181697

DOI: https://doi.org/10.1080/00359191909519985

Permalink: https://www.biodiversitylibrary.org/partpdf/175660

\section{Holding Institution}

Smithsonian Libraries

\section{Sponsored by}

Biodiversity Heritage Library

\section{Copyright \& Reuse}

Copyright Status: Not in copyright. The BHL knows of no copyright restrictions on this item.

This document was created from content at the Biodiversity Heritage Library, the world's largest open access digital library for biodiversity literature and archives. Visit BHL at https://www.biodiversitylibrary.org. 